\title{
Differences between Chinese morphosyllabic and German alphabetic readers in the Stroop interference effect
}

\author{
HENRIK SAALBACH and ELSBETH STERN \\ Max Planck Institute for Human Development, Berlin, Germany
}

\begin{abstract}
The goal of our study was to localize the source of the stronger Stroop interference effect found in morphosyllabic readers as compared with alphabetic readers. Twenty-three Chinese and 24 German undergraduate students were tested in a Stroop paradigm with the following stimuli: color patches, colorneutral words (e.g., friend printed in yellow), incongruent color-associated words (e.g., blood printed in blue), and incongruent color words (e.g., yellow printed in blue). Results revealed no differences in German and Chinese students' response times to color patches. Chinese participants, however, showed longer color naming latencies for neutral words as well as for color words and color-related words. No differences between German and Chinese participants were found when print color latencies for neutral words were subtracted from print color latencies for color words and color-related words. This result does not support theories which suggest that for morphosyllabic readers there is a direct route from orthography to the semantics of a word. We rather argue, with reference to dual route models of reading, that access from print to phonology is faster for morphosyllabic than for alphabetic readers, and therefore interference caused by conflicting phonologies of color name and written word will be stronger in Chinese readers than in German readers.
\end{abstract}

In recent decades, extensive research has addressed the issue of how skilled readers exposed to a written word activate orthographic, phonological, and semantic information stored in the mental lexicon. In comparison with the amount of studies on reading alphabetic scripts, little research has been devoted to character recognition in morphosyllabic writing systems such as Chinese or Japanese Kanji. Given the fundamental differences in the way alphabetic and morphosyllabic writing systems are constructed, it seems obvious that there should also be fundamental differences in the cognitive processes involved in reading both types of script.

Alphabetic scripts consist of about 30 letters that directly represent phonological information. In order to become literate, one has to master grapheme-phoneme conversion rules and to learn about exceptions to these rules for certain words. Morphosyllabic writing systems, in contrast, are composed of several thousand characters, most of them visually complex, each of which represents not a phoneme, but a morpheme. In the case of Chinese, about $90 \%$ of the characters consist of two components: The radical gives a clue to meaning, and the phonetic gives a clue to pronunciation. However, because of historical

We thank Max Coltheart, Shu-Chen Li, Chapnik Smith, Heinz Wimmer, Zhou Xiaolin, Johannes Ziegler, and Liqi Zhu for their helpful comments on earlier versions of this article, and Hella Beister for improving the English. Correspondence should be addressed to E. Stern, Max Planck Institute for Human Development, Lentzeallee 94, D-14195 Berlin, Germany (e-mail: stern@mpib-berlin.mpg.de). changes in language, pronunciations of only about one third of all composed characters are still guided by their phonetics (Hoosain, 1991). The characters represent meaningful units, but their assignation to a specific pronunciation seems mostly arbitrary and will vary between dialects and even languages - for example, between Mandarin and Cantonese. Characters are learned in a more holistic way, without systematic instruction in the use of phonological information (Shu \& Anderson, 1997). Chen (1987) found that the whole character, rather than its strokes and radicals, is the basic unit in processing written Chinese.

On the basis of these characteristics of morphosyllabic scripts, the so-called direct-access hypothesis suggests that skilled readers activate the meaning of a written word through a direct route from an orthographic to a semantic entry in the mental lexicon, bypassing phonological information (Taft \& van Graan, 1998). Direct semantic access can also be expected to gain priority over phonological mediation in reading morphosyllabic script because of the ambiguity of phonological information in the Chinese language. The number of available written characters is much larger than the number of different tone syllables used in spoken Chinese. Therefore, many orthographically and semantically dissimilar characters share the same pronunciation, creating a high degree of homophony.

Empirical support for direct semantic access in Chinese readers has been provided by studies using the semantic categorization task (e.g., Leck, Weekes, \& Chen, 1995) and the semantic priming task (e.g., Zhou \& Marslen-Wilson, 1999), as well as by studies showing the Stroop interfer- 
ence effect to be stronger for Chinese than for English readers (Biedermann \& Tsao, 1979; Lee \& Chan, 2000). The Stroop task requires respondents to name the print color of a presented word rather than merely read this word. For skilled readers, print-color naming takes longer than naming the color of patch controls (Stroop, 1935). Following the rationale of the direct-access hypothesis, the close connection between the orthographic and the semantic entry of words in the mental lexicon makes it particularly hard for morphosyllabic readers to suppress information about the meaning of the written word.

Despite the plausibility of the direct-access hypothesis, several studies have challenged the claim that reading morphosyllabic scripts will proceed without phonological mediation, even if its readers rely on orthographic information more strongly than do alphabetic readers (e.g., Perfetti \& Tan, 1998). A recent finding that has seriously called the direct-access hypothesis into question comes from Spinks, Liu, Perfetti, and Tan (2000). They found a strong Stroop interference effect from orthographically dissimilar homophones of color words, thus suggesting that phonological codes provide early sources of constraint in access to meaning not only for alphabetic but also for morphosyllabic readers. This contradicts the direct-access hypothesis, according to which homophones should only lead to the activation of their own semantics and, therefore, not interfere with the meaning of the color. Nonetheless, the stronger Stroop interference effect for Chinese readers will have to be explained.

\section{Different Components of the Stroop Interference Effect}

The classic Stroop interference effect is computed by subtracting the print-color naming latencies for written incongruent color words from the color naming latencies for patches. Further studies have shown that the cognitive processes responsible for the Stroop interference effect have different components (Klein, 1964; MacLeod, 1991; Sharma \& McKenna, 1998). Incongruent color words result in longer color naming latencies than do color-associated noncolor words (e.g., grass printed in red letters), and these kinds of words themselves produce a stronger Stroop interference effect than do color-neutral words (e.g., friend). Both differences are considered the semantic component of the Stroop interference effect. Smith and Kirsner (1982) developed a Stroop-like task that required participants to name drawn objects with a word written across them (e.g., chair written across the drawing of a hat). They found the semantic interference generated by nouns and adjectives to be comparable for Chinese and English participants.

Naming the print color of color-neutral words takes longer than naming the print color of letter strings that do not result in a word, or than naming the color of patches. These differences are referred to as the phonological component that occurs because of the conflicting phonologies of color name and written word. As a result of extensive reading experience, word-to-response associations are much stronger than color-to-response associations. Several studies have suggested that the phonological component can be traced back to competition in oral response. Keele (1972) did not find Stroop interference for color-neutral words after response modalities were changed from vocal to manual. Coltheart, Woollams, Kinoshita, and Perry (1999) found interference to be weaker for color-neutral words that shared phonemes with the color word to be produced than for words that did not. Contrary to the usual Stroop paradigm, in which the same stimuli are presented repeatedly, Monsell, Taylor, and Murphy (2001) presented each stimulus word only once. In this case, no differences in color naming latencies appeared between color-neutral words and pronounceable letter strings as well as between high-frequency and low-frequency color-neutral words.

\section{Routes From Print to Speech in Morphosyllabic and Alphabetic Readers That Might Affect Stroop Interference}

Recent approaches to modeling the reading processes for alphabetic words, such as the dual route cascaded model, distinguish between a nonlexical and a lexical route (Coltheart, Rastle, Perry, Langdon, \& Ziegler, 2001). Following Coltheart (2000), central aspects of this model are summarized in Figure 1. On the nonlexical route, letter units are converted, by a left-to-right serial process, into phonological units through the use of grapheme-phoneme conversion rules, bypassing the orthographic lexicon. The lexical route starts out with a parallel identification process across letters and leads to the activation of a preexisting entry in the orthographic lexicon. Cascaded processing means that activation on one level is immediately passed on to subsequent levels, which also implies that the lexical and the nonlexical route can work in parallel. Clinical studies suggest that the phonological lexicon can be accessed by a nonsemantic lexical route. One English-speaking stroke patient whose comprehension of written words was severely impaired could nonetheless read aloud words with an irregular grapheme-morpheme relationship (Gerhand, 2001).

Dual route models were developed for the reading of alphabetic scripts, and they therefore can only partly account for character reading. Possible sources of differences are highlighted in Figure 1. Given the unreliable relationship between characters and phonological codes in morphosyllabic scripts, the use of a nonlexical route consisting of systematic grapheme-sound correspondences seems unlikely (Perfetti \& Zhang, 1991; Shen \& Forster, 1999). Therefore, morphosyllabic readers can access the phonological information of a written character only from preexisting entries in the phonological lexicon. A clinical study with demented Japanese patients also suggests the existence of a nonsemantic lexical route for morphosyllabic readers (Sasanuma, Sakuma, \& Kitano, 1992). Patients were able to correctly read aloud words written in the morphosyllabic Kanji script, although their comprehension of the same words was severely impaired.

Coltheart et al. (1999) modeled Stroop interference within the dual route cascaded model, shown in Figure 1: As a result of the color naming instruction, semantic entries related to the print color are activated. At the same 


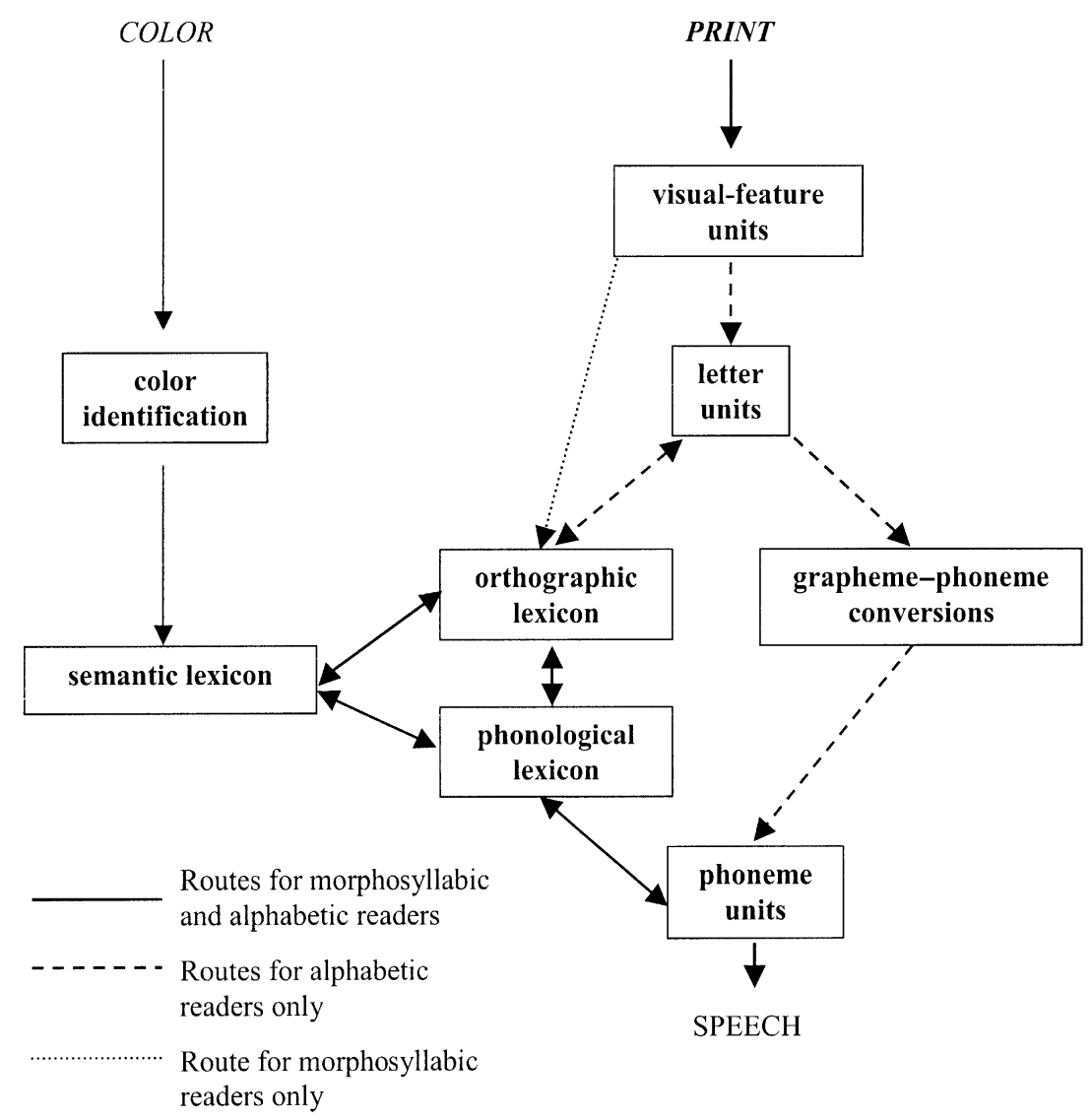

Figure 1. Stroop interference effects for morphosyllabic and alphabetic readers within the framework of dual route models. The figure was adapted from Coltheart et al. (1999).

time, the written word activates lexical and nonlexical routes of reading. The semantic component of the Stroop interference effect may occur because the color identification, as well as the reading of the color word, activates closely related entries in the semantic lexicon, which in turn activate competing information in the phonological lexicon. This competing information will cause conflict when one is accessing the phonemes that form the oral response.

The phonological Stroop component can be traced back to interference in the phonological lexicon or to conflicts in activating phoneme units for preparing speech on the nonlexical route. Interference in the phonological lexicon may occur because the pronunciation of two entire wordsthat is, the color to name and the written word-have to compete with each other. Moreover, accessing an entry of the written word in the phonological lexicon may go along with a spread of activation to related information in the phonological as well as the semantic lexicon, thus providing further sources of interference with the color naming task. Stroop interference on the nonlexical route may occur because the pronunciation of the color, accessed from the phonological lexicon, competes with the pronunciation of phoneme units derived from letters via graphemephoneme-correspondence rules. This kind of nonlexical phonological competition can be expected to be weaker than the competition of entire words in the phonological lexicon. The degree of nonlexical interference has been proven to depend on phonological similarities between the written word and the color to be named. The higher the similarity - particularly at the beginning of the word - the smaller the phonological component seems to be (Coltheart et al., 1999).

The stronger Stroop interference effect in morphosyllabic as compared with alphabetic readers may be localized in the semantic or in the phonological lexicon. Interference in the semantic lexicon may occur because access from print to the semantic entry of the written word is faster in morphosyllabic readers, possibly because there is a direct route from the visual feature to the orthographic lexicon (see Figure 1). As a consequence of this somewhat faster access to the semantic lexicon, interference between the activated entries of the written word and the color can be expected to be stronger than in alphabetic readers. There are, however, also solid reasons to suppose that for morphosyllabic readers interference in the phonological lexicon is stronger as well. The absence of nonlexical processing in this group of readers may result in a particularly rapid access from print to phonology. The earlier the conflicting phonology of the written word is ac- 
tivated, the longer it will take to overcome interferences with the phonology of the color to be named.

The goal of our study is to determine whether there is a stronger Stroop interference effect for German than for Chinese readers and, if this is the case, to find out whether this difference can be traced back to the phonological or to the semantic component, or both. Participants were presented with color patches, color-neutral words, incongruent color-associated words, and incongruent color words. If we should find a stronger increase in naming latencies from color patches to color-neutral words for Chinese readers, this would be traceable to differences in the phonological component. Stronger increases from color-neutral words to incongruent color-associated words and to incongruent color words would be traceable to the semantic component for Chinese readers.

Since some studies (e.g., Chen \& Shu, 2001; Zhou \& Marslen-Wilson, 1999) have called into question findings on phonological processing in accessing the meaning of Chinese characters, we sought to replicate the findings from Spinks et al. (2000) which show that Stroop interference in Chinese readers is also caused by orthographically dissimilar homophones of incongruent color words. In Chinese, fence is pronounced exactly like blue. If phonological mediation is an integral part of Chinese word recognition, interference can be expected to occur if the character for fence is printed in red, yellow, or green. Because homophones are not at all common in German, there was no opportunity for cross-cultural comparison.

\section{METHOD}

\section{Participants}

Twenty-three Chinese undergraduate students of economics from Beijing (10 female, 13 male) and 24 German undergraduate students of psychology from Berlin (17 female, 7 male) participated in the experiment. Because of these different proportions, we included gender as a covariate. All the participants claimed to have normal color vision.

\section{Materials}

The Chinese and German stimuli are shown in Table 1. Thirty-two trials for color patches, 48 trials for neutral words, 48 trials for colorassociated words, and 48 trials for color words were presented in randomized order to the German and the Chinese participants. The Chinese participants received 48 additional trials for the homophones. There were 5 practice trials in each condition. The trials for color words and color-associated words, as well as for Chinese homophones, involved all combinations of characters and colors except the congruent ones. The Chinese stimuli were the exact translation of the German stimuli in the color word and in the neutral word conditions. Only in the color-associated word condition was the Chinese word for blood replaced by the word for sun. This was necessary because the word for blood (/xue(3)/) is a homophone of the word for snow. Sun is mostly associated with the color red in China. The (same-tone) homophones of the Chinese color words used in an additional condition for the Chinese sample were orthographically and semantically different from the color words. All stimulus words were words frequently used in China and Germany, respectively. In this experiment, the stimuli always appeared in the traditional Stroop colors of red, green, yellow, or blue, with color words and color-associated words always in an incongruent condition.

\section{Procedure}

Each stimulus was presented on a color monitor, and the participants were seated about $60 \mathrm{~cm}$ from the screen. The presentation of the stimuli was signaled by an eye fixation cross ("+") in the center of the screen and accompanied by a bleep sound. After 1,500 msec, the eye fixation cross was replaced by the stimulus, which remained on the screen for $2 \mathrm{sec}$ or until the participants responded to it, whichever was shorter. The participants were required to name the color of the stimulus as quickly as possible, the time between stimulus onset and reaction onset being the naming latency. The participants' vocalizations triggered a voice key interface with a computer.

Table 1

Written Chinese and German Words Used in the Study, Their Chinese Pronunciations, and Their Meanings in English

\begin{tabular}{cllll}
\hline & \multicolumn{4}{c}{ Condition } \\
\cline { 2 - 5 } & Color Word & Color Associate & Neutral Word & Homophone \\
\hline Item & Red & Sun & Town & Flood \\
Chinese word & 红 & 太阳 & 城 & 洪 \\
Pronunciation & /hong(2)/ & /tai(4)yang(2)/ & /cheng(2)/ & /hong(2)/ \\
German word & Rot & Blut (blood) & Stadt & \\
Item & Yellow & Snow & Bus, Car & Emperor \\
Chinese word & 黄 & 雪 & 车 & 皇 \\
Pronunciation & /huang(2)/ & /xue(3)/ & /che(1)/ & /huang(2)/ \\
German word & Gelb & Schnee & Bus & \\
Item & Green & Gras & Book & Law, Rule \\
Chinese word & 绿 & 草 & 书 & 律 \\
Pronunciation & /lü(4)/ & /cao(3)/ & /shu(1)/ & /lü(4)/ \\
German word & Grün & Gras & Buch & \\
Item & Blue & Sky & Map, Picture & Fence \\
Chinese word & 蓝 & 天 & 图 & 栏 \\
Pronunciation & /lan(2)/ & /tian(1)/ & /tu(2)/ & lan(2)/ \\
German word & Blau & Himmel & Karte & \\
\hline
\end{tabular}

Note-Numbers in parentheses refer to the tone in spoken Mandarin. 
After reaction onset, the screen remained blank for $1 \mathrm{sec}$, after which the eye fixation cross reappeared.

\section{RESULTS}

In all stimulus conditions, error rates were very low $(1 \%-2 \%)$ and therefore were not considered further. Naming latencies over 1,200 msec were excluded (less than $2 \%)$. For each participant, the mean naming time for each stimulus condition was computed. Mean naming latencies and standard deviations for the four stimulus conditions presented to participants of both writing systems are shown in Table 2 . A $2 \times 4$ repeated measures analysis of variance revealed main effects for stimulus condition $[F(3,45)=173.33, p<.001]$ and writing system $[F(1,45)=$ $10.30, p<.01]$, as well as a significant interaction $[F(3,45)=4.57, p<.01]$. Post hoc tests revealed significant differences between Chinese and Germans for neutral words, inconsistent color-associated noncolor words, and inconsistent color words (all $p \mathrm{~s}<.01$ ), but not for color patches $(p>.20)$. A stronger classic Stroop interference effect (difference between latencies for incongruent color words and color patches; Chinese, $M=168 \mathrm{msec}$, $S D=50$; German, $M=122 \mathrm{msec}, S D=48$ ) was revealed for the Chinese sample $[t(45)=3.13, p<.01]$.

In order to localize the differences between German and Chinese readers, phonological and semantic components were determined by computing the differences in color naming latencies in the following order: (1) color word, (2) color-associated word, (3) neutral word, and (4) color patch. The results are shown in Figure 2. A 2 (writing system) $\times 4$ (stimulus condition) repeated measures analysis with gender as a covariate revealed main effects for writing system $[F(1,44)=8.19, p<.01]$ and stimulus condition $[F(3,44)=13.82, p<.01]$, as well as an interaction $[F(3,44)=4.57, p<.01]$. The increase of naming laten-
Table 2

Mean Naming Latencies (in Milliseconds) and Standard Deviations for the Four Stimulus Conditions for Chinese and German Participants

\begin{tabular}{|c|c|c|c|c|c|c|c|c|}
\hline & \multicolumn{2}{|c|}{$\begin{array}{l}\text { Color } \\
\text { Patches }\end{array}$} & \multicolumn{2}{|c|}{$\begin{array}{l}\text { Neutral } \\
\text { Words }\end{array}$} & \multicolumn{2}{|c|}{$\begin{array}{l}\text { Color-Associated } \\
\text { Words }\end{array}$} & \multicolumn{2}{|c|}{$\begin{array}{l}\text { Color } \\
\text { Words }\end{array}$} \\
\hline & $M$ & $S D$ & $M$ & $S D$ & $M$ & $S D$ & $M$ & $S D$ \\
\hline Gern & 569 & 46 & 601 & 41 & 621 & 54 & 692 & 52 \\
\hline Chinese & 588 & 48 & 650 & 64 & 677 & 73 & 756 & 60 \\
\hline
\end{tabular}

cies from color patches to neutral words was stronger for Chinese than for German participants $[F(1,44)=5.76$, $p<.05$ ], but both groups did not differ in the increase from neutral to color-associated words, and from colorassociated to color words (all $F \mathrm{~s}<1$ ). None of the gender effects was significant (all $p \mathrm{~s}>.20$ ). By considering incongruent color words as well as color-associated words, we divided the semantic component into two parts, which might have affected significance testing. The results of an additional analysis, in which we considered incongruent color words, neutral words, and patches only, however, brought no changes to the picture in any of its aspects. Both groups did not differ in the increase in naming latencies from neutral to incongruent color words $(p>.20)$. Altogether, the results suggest that differences between Chinese and German participants are due to the phonological component rather than the semantic component of the Stroop interference effect.

\section{Stroop Interference Caused by Homophones in the Chinese Sample}

Stroop interference (computed by subtracting color naming latencies for patches) was stronger for homophones of incongruent color words $(M=152 \mathrm{msec}, S D=$ $60)$ than for neutral words $[M=62 \mathrm{msec}, S D=51)$;

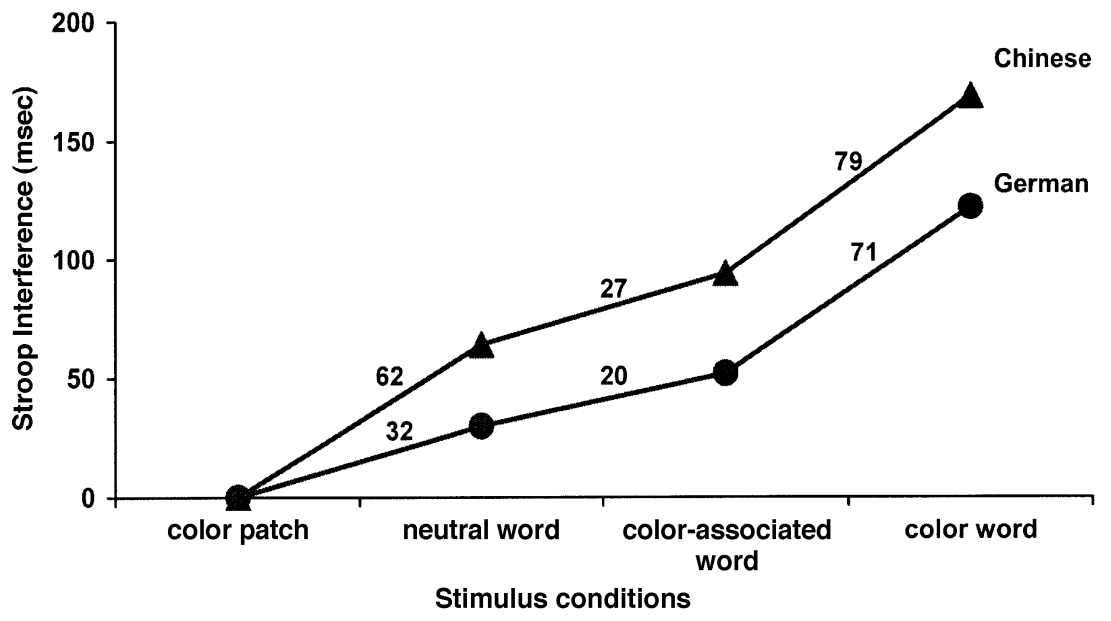

Figure 2. Mean Stroop interferences for neutral, color-associated and color words computed by subtracting the naming latencies for color patches separately for Chinese and German participants. The numbers on the lines indicate the differences in naming latencies between neighboring stimulus conditions. 
$F(1,22)=75.9, p<.01]$, as well as for incongruent colorassociated words $[M=89 \mathrm{msec}, S D=50 ; F(1,22)=$ $23.8, p<.01]$. Stroop interference for incongruent color words $(M=168 \mathrm{msec}, S D=59)$ was marginally stronger than Stroop interference for homophones $[F(1,22)=3.06$, $p<.10]$.

\section{DISCUSSION}

In accordance with earlier findings, we obtained a stronger Stroop interference effect for Chinese morphosyllabic than for German alphabetic readers. Although Chinese and Germans did not differ in their naming latencies for color patches, Chinese were found to have longer latencies for color-neutral words, inconsistent colorrelated noncolor words, and inconsistent color words. When color naming latencies for neutral words were subtracted from naming latencies for either incongruent color or color-related words, however, no differences between Chinese and Germans were found, which indicates that the two groups did not differ in the extent of semantic interference. The widespread claim according to which access from print to semantics is faster for morphosyllabic than for alphabetic readers was not confirmed by our data. Instead, our data suggest that access from print to phonology is faster in Chinese than in German readers.

The central finding of our study is that the stronger Stroop interference in Chinese readers can be entirely traced back to the phonological component. This became apparent in the longer color naming latencies for color-neutral words for Chinese as compared with German readers. In contrast to color patches, neutral words prompt phonologies that compete with the phonology of the color to be named. This conflict slows down the production of the correct phonology of the color name in Chinese as well as in German readers. However, because of the absence of nonlexical processing, Chinese readers access the phonology of the written word somewhat faster than do their German counterparts. As a consequence, interference between the phonology of the written word and that of the color to be named is stronger for morphosyllabic readers and takes longer to overcome.

That access from print to phonology must in fact be particularly fast for Chinese is confirmed by the strong homophone effect. The findings of Spinks et al. (2000) on morphosyllabic readers, according to which homophones of incongruent color words produced a stronger Stroop interference effect than did color-neutral words, was replicated and confirmed for our Chinese sample. In our study, the interference caused by incongruent color words was only marginally stronger than interference caused by homophones of incongruent color words. This strong homophone Stroop effect provides additional evidence for very fast access from print to phonology in Chinese, since readers activate semantics via phonological mediation fast enough to cause interference with the semantics of the color to be named.
Stroop effects caused by Chinese homophones contrast with findings recently reported by Caramazza, Costa, Miozzo, and $\mathrm{Bi}$ (2001), who suggested independent phonological representation for homophones in Chinese as well as in other languages. Our data clearly support a sharedphonological-representation view: Reading the Chinese homophone for blue meaning fence interferes significantly more with naming the color yellow than does a color-neutral word; it interferes nearly as much as a color word itself. The contradictory findings might be rooted in methodological differences. Caramazza et al. (2001) used a picture naming procedure instead of unintended word reading. Pictures have direct access to the semantic lexicon, whereas words first activate phonological entries, and these different routes to speech production may have caused the conflicting results.

It is widely accepted that phonology is the key to explaining differences in the cognitive processes involved in reading morphosyllabic as compared with alphabetic scripts. Views fundamentally differ, however, on how the phonological lexicon is involved in accessing speech from printed characters. According to the direct-access hypothesis, morphosyllabic readers can do without accessing phonology, but alphabetic readers cannot. Meanwhile, however, growing evidence points to a contrary position. Reading words printed in a morphosyllabic script obviously goes along with early phonological activation, cascading over the mental lexicon and, thereby, also guiding semantic activation. Models of word production that rely on a topdown process from semantics to phonology (for an overview, see Levelt, 1999) can hardly account for morphosyllabic reading processes. Rather, the particularly strong phonological Stroop component in our Chinese sample, as well as the existence of a homophone Stroop effect in this group, suggests that coactivation of semantic and phonological entries is a key feature for morphosyllabic readers.

\section{REFERENCES}

Biedermann, I., \& Tsao, Y. C. (1979). On processing Chinese ideographs and English words: Some implications from Stroop-test results. Cognitive Psychology, 11, 125-132.

Caramazza, A., Costa, A., Miozzo, M., \& BI, Y. (2001). The specificword frequency effect: Implications for the representation of homophones in speech production. Journal of Experimental Psychology: Learning, Memory, \& Cognition, 27, 1430-1450.

CHEN, H. C. (1987). Character detection in reading Chinese: Effects of context and display format. Chinese Journal of Psychology, 29, 4550 .

Chen, H. C., \& Shu, H. (2001). Lexical activation during the recognition of Chinese characters: Evidence against early phonological activation. Psychonomic Bulletin \& Review, 8, 511-518.

Coltheart, M. (2000). Dual routes from print to speech and dual routes from print to meaning: Some theoretical issues. In A. Kennedy, R. Radach, D. Heller, \& J. Pynte (Eds.), Reading as a perceptual process (pp. 475-490). Amsterdam: Elsevier.

Coltheart, M., Rastle, K., Perry, C., Langdon, R., \& Ziegler, J. (2001). DRC: A dual route cascaded model of visual word recognition and reading aloud. Psychological Review, 108, 204-256.

Coltheart, M., Woollams, A., Kinoshita, S., \& Perry, C. (1999). A 
position-sensitive Stroop effect: Further evidence for a left-to-right component in print-to-speech conversion. Psychonomic Bulletin \& Review, 6, 456-463.

GERHAND, S. (2001). Routes to reading: A report of a non-semantic reader with equivalent performance on regular and exception words. Neuropsychologia, 39, 1473-1484.

Hoosain, R. (1991). Psycholinguistic implications for linguistic relativity: A case study of Chinese. Hillsdale, NJ: Erlbaum.

KeELE, S. W. (1972). Attention demands of memory retrieval. Journal of Experimental Psychology, 93, 245-248.

KLEIN, G. S. (1964). Semantic power measured through the interference of words with color-naming. American Journal of Psychology, 77, 576-588.

LeCK, K. J., WeEkes, B. S., \& CHEN, M. J. (1995). Visual and phonological pathways to the lexicon: Evidence from Chinese readers. $\mathrm{Mem}$ ory \& Cognition, 23, 468-476.

LEE, T. M. C., \& CHAN, C. C. H. (2000). Stroop interference in Chinese and English. Journal of Clinical \& Experimental Neuropsychology, 22, 465-471.

LEVELT, W. J. M. (1999). Models of word production. Trends in Cognitive Sciences, 3, 223-232.

MACLEOD, C. M. (1991). Half a century of research on the Stroop effect: An integrative review. Psychological Bulletin, 109, 163-203.

Monsell, S., TAYlor, T. J., \& MurPhy, K. (2001). Naming the color of a word: Is it responses or task sets that compete? Memory \& Cognition, 29, 137-151.

PeRfeTt C. A., \& TAN, L. H. (1998). The time-course of graphemic, phonological, and semantic activation in Chinese character identification. Journal of Experimental Psychology: Learning, Memory, \& Cognition, 24, 101-118.

PerfetTI, C. A., \& ZhANG, S. (1991). Phonological processes in read- ing Chinese words. Journal of Experimental Psychology: Learning, Memory, \& Cognition, 17, 633-643.

Sasanuma, S., Sakuma, N., \& Kitano, K. (1992). Reading Kanji without semantics: Evidence from a longitudinal study of dementia. $\underline{\mathrm{Cog}}$ nitive Neuropsychology, 9, 465-486.

Sharma, D., \& McKenna, F. P. (1998). Differential components of the manual and vocal Stroop tasks. Memory \& Cognition, 26, 1033-1040.

SHEN, D., \& ForSTER, K. (1999). Masked phonological priming in reading Chinese depends on the task. Language \& Cognitive Processes, 14, 429-460.

SHU, H., \& ANDERSON, R. C. (1997). Role of radical awareness in the character and word acquisition of Chinese children. Reading Research Quarterly, 32, 78-89.

SMith, M. C., \& KIRSNER, K. (1982). Language and orthography as irrelevant features in colour-word and picture-word Stroop interference. Quarterly Journal of Experimental Psychology, 34A, 153-170.

Spinks, J. A., LiU, Y., Perfetti, C. A., \& Tan, L. H. (2000). Reading Chinese characters for meaning: The role of phonological information. Cognition, 76, B1-B11.

Stroop, J. R. (1935). Studies of interference in serial verbal reactions. Journal of Experimental Psychology, 18, 643-662.

TAFT, M., \& VAN GRAAN, F. (1998). Lack of phonological mediation in a semantic categorization task. Journal of Memory \& Language, $\mathbf{3 8}$, 203-224.

Zhou, X., \& Marslen-Wilson, W. (1999). Phonology, orthography, and semantic activation in reading Chinese. Journal of Memory \& Language, 41, 579-606.

(Manuscript received November 19, 2002; revision accepted for publication July 8, 2003.) 